\title{
ADSORÇÃO DE CONTAMINANTES DO BIODIESEL POR FIBRAS DE BAGAÇO MODIFICADAS NA SUPERFÍCIE
}

Renata de Souza Oliveira ${ }^{a}$, Mariana Fornazier Borges ${ }^{a}$, Andressa Tironi Vieira ${ }^{b}$, Mariana Alves Henrique ${ }^{a}$, Elaine A. Mundim Ribeiro ${ }^{a}$, Franciel Aureliano Bezerra ${ }^{c}$, Flaysner Magayver Portela ${ }^{a}$, Nilson Roberto Pereira ${ }^{b}$, Rosana Maria Nascimento de Assunção ${ }^{\mathrm{b}}$ e Reinaldo Ruggiero ${ }^{\mathrm{a}, *}$

anstituto de Química, Universidade Federal de Uberlândia, 38400-902 Uberlândia - MG, Brasil

bUniversidade Federal de Uberlândia, Campus Pontal, 38304-402 Ituiutaba - MG, Brasil

'Instituto de Engenharia Química, Universidade Federal de Uberlândia, 38400-902 Uberlândia - MG, Brasil

Recebido em 25/05/2017; aceito em 24/10/2017; publicado na web em 04/12/2017

\begin{abstract}
ADSORPTION OF BIODIESEL CONTAMINANTS BY SURFACE-MODIFIED BAGASSE FIBERS. Sugarcane bagasse fibers chemically modified on its surface were used to adsorb contaminants from biodiesel. Two biodiesel samples were used as adsorbates: crude and washed biodiesel. The contaminants were mainly glycerol and water, but also ions, and methanol. The biodiesel is usually washed, in order to remove most of the contaminants, but the procedure introduces large amounts of water, which are further difficult to remove, because the biodiesel acting as an acceptor of hydrogen bond. The adsorbent used in this work was proved to be very efficient to remove the contaminants and also to remove water from the washing the crude biodiesel. The contaminants adsorbed from biodiesel were identified by thermal analyses (DSC and DTA) of the fibers (adsorbent) and of the biodiesel (adsorbate) by comparing the results with the pure biodiesel. The proportion of free glycerol showed high adsorption efficiency for the crude biodiesel. A total amount of $1.34 \mathrm{~g}$ of fibers was estimated as being needed for its complete removal. The mass of bagasse fibers added (up to $1 \mathrm{~g}$ ) in a fixed volume of biodiesel was a relevant condition, as the saturation in fibers started at around $0.70 \mathrm{~g}$ cleaning up to about $98 \%$ removal of the impurities.
\end{abstract}

Keywords: adsorption; bagasse; biodiesel; contaminants.

\section{INTRODUÇÃO}

O suprimento de energia ainda é majoritariamente dependente dos combustíveis fósseis: petróleo, carvão e gás natural. Considerando que as fontes fósseis são finitas, os gases da exaustão, produtos da combustão, são fortemente prejudiciais à sustentabilidade ambiental e os combustíveis têm o preço afetado por conflitos devido a instabilidades políticas, nas áreas de grande produção, são motivos que estimulam mais a ampliação da busca por fontes alternativas de energia e combustíveis renováveis. No cenário de inovação do mercado energético mundial, o Brasil tem destaque devido ao seu potencial de produção de biocombustíveis, tanto para suprir sua demanda interna quanto para exportar. ${ }^{1}$

A grande extensão territorial do Brasil (é o quinto país de maior extensão de área territorial do globo) e a sua localização geoclimática, situado em sua maior parte na zona tropical, favorece produção de biomassas diversificadas, sendo praticamente toda sua extensão aproveitável para a exploração agropecuária. ${ }^{2}$ Assim sendo, é viável a destinação de espaços para a cultura de vegetais oleaginosos, visando à produção de biocombustíveis.

Biocombustíveis são substâncias derivadas de biomassa em base renovável, podendo substituir parcial ou totalmente os combustíveis fósseis. São empregados diretamente ou com poucas alterações, em motores a combustão interna ou, também, para outros tipos de geração de energia. $^{3}$

Os principais biocombustíveis líquidos brasileiros são o etanol, extraído principalmente da sacarose da cana-de-açúcar, e o biodiesel, produzido a partir de óleos vegetais ou de gorduras animais. ${ }^{4}$

Segundo a Resolução ANP n ${ }^{\circ} 30 / 2016,{ }^{5}$ biodiesel é o combustível composto de alquil ésteres de ácidos carboxílicos de cadeia longa,

*e-mail: reinaldo@ufu.br produzidos a partir da transesterificação e/ou esterificação de trialcilgliceróis de origem vegetal ou animal, e que atenda a especificação preconizada no Regulamento Técnico $n^{\circ} 3 / 2014$, parte integrante da Resolução ANP n ${ }^{\circ} 45$ de 25 de agosto de $2014,{ }^{6}$ ou outra que venha a substituí-la.

Assim como o etanol, o biodiesel tem significativas vantagens ambientais. Estudos do National Biodiesel Board ${ }^{7}$ (associação que representa a indústria de biodiesel nos Estados Unidos) demonstraram que a queima de biodiesel pode gerar em média $48 \%$ menos monóxido de carbono (relativamente ao ciclo global do $\mathrm{CO}_{2}$ ); $47 \%$ menos material particulado (que chega aos pulmões) e $67 \%$ menos hidrocarbonetos. Como esses percentuais variam de acordo com a quantidade de biodiesel adicionado ao diesel de petróleo, essas reduções ocorrem de modo proporcional. O biodiesel é adicionado ao diesel de petróleo em proporções regulamentadas por legislações específicas, recebendo a denominação de BX, em que X representa a porcentagem volumétrica de biodiesel adicionada ao petrodiesel.

Existem inúmeras matérias-primas que podem ser usadas para a produção de biodiesel, como de plantas oleaginosas (milho, girassol, algodão, soja, pinhão-manso, baru, entre outras) e gorduras e óleos residuais de frituras. Entretanto, a matéria-prima mais utilizada na produção de biodiesel brasileiro atualmente ainda é o óleo de soja, com 69,30\%, conforme o Boletim Mensal do Biodiesel da ANP de janeiro de $2017 .{ }^{8}$

A soja (Glycine $\max$ L. Merrill) responde pela maior parcela do óleo vegetal brasileiro por razões principalmente econômicas, mas também tradicionais. A oleaginosa tem sua cadeia produtiva bem estruturada no país, com tecnologias de produção definidas e modernas e uma ampla rede de pesquisa agrícola. É uma cultura adaptada a todo o território nacional, com igual eficiência de cultivo, sendo seu ciclo de produção curto, de 4 a 5 meses. Apesar de outras oleaginosas serem bem mais produtivas, o óleo de soja pode ser utilizado tanto 
diretamente para consumo humano quanto para produzir biodiesel, ou para usos na indústria química, além de produzir o farelo proteico utilizado em rações para animais produtores de carne, leite, ovos, fato que constitui em uma grande vantagem. ${ }^{9}$

A comercialização de biodiesel requer conformidades técnicas com rigorosas normas e padrões internacionais, como a EN 14214 (European Standard) e a ASTM D6751 (American Society for Testing and Materials), e obter produtos que se enquadrem nesses padrões é tecnicamente difícil. ${ }^{10}$ Pesquisas a minimizar problemas da produção, estocagem e abastecimento do biodiesel contribuem para o aumento de sua qualidade, sua aceitação no mercado internacional e consequente retorno financeiro. ${ }^{11}$

O método para a produção industrial de biodiesel mais utilizado na escala global é a transesterificação, reação entre um trialcilglicerol e um álcool de cadeia curta, sob ação de um catalisador, que resulta em uma mistura de ésteres, que constitui o biodiesel. A reação resulta também, como coproduto, no glicerol ou a glicerina, que, em altas concentrações no biodiesel, pode provocar problemas de armazenamento, formação de depósitos, entupimento de bicos injetores do motor e emissões de aldeídos. ${ }^{12}$

A água, oriunda do processo de lavagem do biodiesel para remoção da glicerina livre residual, gera complicações ao produto, como a hidrólise do biodiesel, resultando em ácidos graxos livres, aumento na proliferação de micro-organismos e corrosão em tanques de estocagem. Naturalmente, o biodiesel apresenta certo grau de hidroscopicidade; é, pois, importante o monitoramento do teor de água. ${ }^{10}$

A ocorrência de contaminantes remanescentes no biodiesel, como glicerol e água, provocam a deterioração de peças dos automóveis, diminuição da estabilidade oxidativa, crescimento bacteriano e a consequente degradação do biodiesel, entre outras dificuldades na sua utilização como combustível substituinte dos derivados do petróleo. ${ }^{13}$

A separação e a purificação do biodiesel bruto por processos adsortivos é uma alternativa promissora na remoção de contaminantes, pelo menor uso de água, e no tratamento de efluentes gerados, além da capacidade de reutilização do material adsortivo. ${ }^{14,15} \mathrm{~A}$ purificação do biodiesel pela adsorção em bagaço de cana-de-açúcar modificado superficialmente aponta uma opção vantajosa.

Segundo Silva et al.,${ }^{16}$ o processo de carboximetilação de lignina de bagaço de cana-de-açúcar produz materiais com elevada pureza e termicamente estáveis, capazes de se complexar com determinados metais, tornando-os excelentes adsorventes de corantes têxteis em solução aquosa. Carvalho et al. ${ }^{17}$ verificou a capacidade de adsorção de fosfatos em água por fibras de bagaço de cana-de-açúcar quimicamente modificados. Ambos os trabalhos reportam a facilidade e a viabilidade com que materiais ligno-celulósicos oriundos do bagaço de cana têm para adsorver moléculas polares.

O setor sucroenergético no Brasil aproveita em larga escala vários subprodutos do processo industrial de beneficiamento da cana-de-açúcar, entre eles o uso do bagaço. O bagaço de cana-de- açúcar já tem diversas destinações práticas, como geração de bioetanol (etanol de segunda geração), energia térmica e termoelétrica, alimentação para gado, peças de artesanato, matéria-prima na produção de celulose, entre outras. ${ }^{18}$ As variadas formas de utilização do bagaço e da lignina, além de minimizar impactos ambientais, agregam valor às cadeias produtivas. ${ }^{19,20}$ No contexto de biorrefinarias e química verde, é possível aliar o aproveitamento do bagaço de cana-de-açúcar à otimização da produção industrial do biodiesel de soja.

A proporção de bagaço de cana que remanesce da moagem da cana-de-açúcar nas usinas do país depende da proporção de fibras das cultivares de cana-de-açúcar usadas como matéria-prima. As variedades nomeadas com prefixo da fibra RB (lançadas pela rede
RIDESA) respondem por $58 \%$ da área de plantio nas atuais safras brasileiras e, de um modo geral, apresentam um teor aproximado de 270 a $290 \mathrm{~kg}$ de bagaço em cada tonelada de cana processada. ${ }^{21}$ Tomando como base a estimativa de produção de 684,77 milhões de toneladas de cana-de-açúcar na safra 2016/2017, segundo levantamento feito em agosto de 2016 pela Companhia Nacional de Abastecimento - CONAB,${ }^{21}$ restariam, em média, 198,65 milhões de toneladas na forma de bagaço de cana, ou seja, 29\% do total da produção de cana-de-açúcar do país, que poderiam ser aproveitados de variadas formas. Neste trabalho, desenvolvemos um adsorvente utilizando fibras do bagaço de cana-de-açúcar, com pequena modificação na superfície da fibra para favorecer a adsorção de contaminantes (glicerol e água) do biodiesel. O material mostrou grande eficiência, que poderá ter impacto favorável na economia de água de lavagem e em processos de purificação a seco do biocombustível.

\section{PARTE EXPERIMENTAL}

\section{Reagentes}

Para a reação de transesterificação, foi utilizado o óleo refinado de soja comercial (ABC, Brasil), hidróxido de potássio $85 \%$ e metanol 99,8\% (ambos, Dinâmica). O bagaço de cana-de-açúcar foi obtido de usina de produção de etanol da região do Triângulo Mineiro e foi purificado (Soxhlet) com ciclohexano 99\% (Synth), etanol 99,5\% (Dinâmica) e água destilada. Para a carboximetilação das fibras de bagaço foram utilizados etanol 99,5\% (Dinâmica), hidróxido de sódio 97\% (Dinâmica), ácido monocloroacético 99\% (Vetec) e ácido acético 99,7\% (Glacial; Isofar).

\section{Síntese do biodiesel de soja}

O biodiesel foi produzido por transesterificação sob catálise homogênea alcalina, a partir do óleo refinado de soja, pela rota metílica, na temperatura ambiente. Foram solubilizadas 4,7 g do catalisador hidróxido de potássio em $67 \mathrm{~g}$ de metanol sob agitação magnética. A solução foi transferida lentamente para um béquer contendo $200 \mathrm{~g}$ de óleo refinado de soja; a mistura permaneceu sob agitação magnética constante por 1 hora.

Ao término do tempo de reação, foram confeccionadas placas cromatográficas de alumina em camada delgada (CCD) para monitoramento do término da reação de transesterificação. A eluição da CCD foi realizada com solvente constituído de hexano, acetato de etila e ácido acético glacial, na proporção respectiva de 7:2:1. As placas foram reveladas em uma cuba contendo vapores de iodo sublimado. Em seguida, a mistura foi transferida para um funil de decantação para a separação das fases imiscíveis: glicerol (fase inferior) e biodiesel (fase superior). Após três horas em repouso, em média, foi possível separar quantitativamente a glicerina, o que garante um biodiesel de maior qualidade.

O biodiesel retirado foi acondicionado em frasco âmbar, para manipulação em etapas posteriores. A síntese do biodiesel foi repetida diversas vezes para se conseguir o volume necessário aos testes planejados para o decorrer do trabalho.

\section{Purificação do biodiesel com água destilada}

A lavagem do biodiesel com água quente é frequentemente utilizada para a remoção de componentes hidrossolúveis. O processo é simples, eficiente, barato e tem como propósito remover substâncias alcalinas, glicerol e acilgliceróis do biodiesel. ${ }^{22,23}$ Contudo, por ser realizado em etapas repetidas, torna-se lento e gera grandes volumes de efluentes, produzindo danos se descartado diretamente no meio 
ambiente. Tratar o resíduo antes do descarte é difícil e dispendioso, o que leva a aumento do custo de produção do biocombustível. ${ }^{22-26}$

$\mathrm{O}$ biodiesel lavado, para que atenda às normas de qualidade especificadas, precisa antes passar por uma etapa de desidratação com remoção completa da água. ${ }^{27}$

Uma amostra de $250 \mathrm{~mL}$ de biodiesel bruto foi transferida para um funil de decantação e neutralizada na proporção volumétrica de 1:4 com solução de ácido clorídrico $1 \mathrm{~mol} \mathrm{~L}^{-1}$. Em seguida, foram efetuadas sucessivas lavagens com água destilada aquecida a $60{ }^{\circ} \mathrm{C}$. O procedimento de lavagem foi repetido por cinco vezes até obter-se fração aquosa pós-lavagem incolor. Após a separação das fases oleosa e aquosa, o biodiesel foi transferido para um frasco âmbar para posterior análise físico-química.

\section{Desidratação do biodiesel com sílica}

Foram destinados cerca de $200 \mathrm{~mL}$ do biodiesel lavado para a desidratação com sílica gel. Um funil de Büchner foi acoplado a um frasco kitassato de $500 \mathrm{~mL}$ e conectado à mangueira da bomba de vácuo. O funil foi coberto com uma camada de sílica em pó e espessura de cerca de $2 \mathrm{~cm}$. O biodiesel foi passado pela sílica. O procedimento foi repetido diversas vezes. Após a secagem, a amostra foi acondicionada em frasco âmbar para ser caracterizada e servir de comparativo de eficiência com relação à purificação do biodiesel pelo material adsorvente construído no presente trabalho.

\section{Preparação das fibras de bagaço de cana}

O bagaço de cana-de-açúcar foi triturado em liquidificador comercial e passado manualmente em peneira para separação por tamanho, sendo selecionadas aquelas na faixa de 20 mesh. As fibras foram mantidas em um almofariz de porcelana em estufa a $110^{\circ} \mathrm{C}$, durante 24 horas, para a diminuição da umidade do material.

\section{Purificação das fibras}

As fibras foram purificadas em montagem de um sistema de extração com suporte universal, Soxhlet, condensador, balão de fundo chato de $1.000 \mathrm{~mL}$ e manta aquecedora. No balão foram colocados $200 \mathrm{~mL}$ de ciclohexano e $200 \mathrm{~mL}$ de etanol (1:1, v:v) durante 48 horas. Ao término desse tempo, a solução foi substituída por 500 $\mathrm{mL}$ de água e a extração prosseguiu por 24 horas. Em seguida as fibras foram secas em estufa a $110^{\circ} \mathrm{C}$, durante 3 horas. Essas fibras de bagaço de cana-de-açúcar purificadas foram nomeadas BCAP.

\section{Carboximetilação das fibras}

Para a modificação superficial das fibras de bagaço (carboximetilação), foram misturados em um béquer sob agitação magnética com aquecimento em $60{ }^{\circ} \mathrm{C}$ por 3 horas: $540 \mathrm{~mL}$ de etanol (95\%) e $20 \mathrm{~g}$ das fibras purificadas. Durante os 30 minutos iniciais, foram gotejados $53 \mathrm{~mL}$ de solução aquosa de hidróxido de sódio $40 \%$, permanecendo sob agitação por mais uma hora e meia; na última hora, foram adicionados $24 \mathrm{~g}$ de ácido monocloroacético. A suspensão foi neutralizada com ácido acético, filtrada em bomba a vácuo e lavada com $600 \mathrm{~mL}$ de etanol (95\%). Em seguida, foi secada em estufa a $110^{\circ} \mathrm{C}$ por 3 horas. Essas fibras de bagaço de cana-de-açúcar carboximetiladas foram chamadas de BCAC.

\section{Determinação do teor de íons $\mathrm{Na}^{+}$incorporados nas fibras após reação de carboximetilação}

A quantidade sódio nas amostras BCAP e BCAC foi determinada por espectrometria de emissão atômica - fotometria de chama -, em um equipamento da marca Analyser, modelo 910 MS.

A solução empregada na digestão da amostra foi uma mistura de $\mathrm{H}_{2} \mathrm{SO}_{4}$ concentrado e $\mathrm{H}_{2} \mathrm{O}_{2}(35 \%$ em volume) na proporção aproximada de 3:1. Cerca de $20 \mathrm{mg}$ da amostra foram adicionados em $10 \mathrm{~mL}$ de ácido sulfúrico em um Erlenmayer e, em seguida, o peróxido de hidrogênio foi adicionado lentamente até a digestão total da amostra. As diluições finais dos extratos foram para $250 \mathrm{e}$ $300 \mathrm{~mL}$ respectivamente. Desse extrato foi tomada uma alíquota de $1 \mathrm{ml}$ para um volume final de $100 \mathrm{~mL}$ para a realização das leituras. A diferença da quantidade de sódio entre as duas amostras foi tomada como a quantidade de grupos carboxilatos devido à carboximetilação das fibras.

\section{Testes de adsorção em biodiesel bruto}

Isotermas de adsorção foram construídas a partir de diferentes quantidades (massas) de fibras de bagaço carboximetiladas (BCAC), em um volume fixo de $10 \mathrm{~mL}$ do biodiesel bruto, por 24 horas. O biodiesel bruto é aquele obtido após a retirada da fase mais densa, contendo o glicerol, antes da lavagem com água. Foram testadas massas de adsorvente entre $0,05 \mathrm{~g} \mathrm{e} 1 \mathrm{~g}$.

Frascos âmbar de $30 \mathrm{~mL}$ foram utilizados como suporte para os testes de adsorção. Em cada frasco, foram adicionados $10 \mathrm{~mL}$ de biodiesel bruto. Posteriormente, foram adicionadas as massas do material adsorvente. Os frascos foram rapidamente fechados com batoque e tampa, evitando a absorção da umidade do ar no teste. As misturas permaneceram em repouso durante 24 horas. A temperatura das amostras foi medida antes e depois da contagem do tempo e mantidas em sala climatizada a $25 \pm 1^{\circ} \mathrm{C}$ ao longo do tempo dos testes. Após 24 horas de teste, o material adsorvente foi separado do biodiesel bruto por filtração simples com papel de filtro e ambos (biodiesel bruto e BCAC) foram colocados em novos frascos âmbar para análises posteriores.

\section{Testes de adsorção em biodiesel lavado}

O primeiro teste avaliou a retenção de contaminantes no biodiesel bruto através do material adsorvente, em especial o glicerol e a água. Na sequência dos experimentos, procedeu-se da mesma forma, trocando apenas o biodiesel bruto pelo biodiesel lavado.

Foram adicionadas, novamente, diferentes massas em frascos âmbar para o teste de adsorção em $10 \mathrm{~mL}$ de biodiesel lavado em cada frasco. As alíquotas de cada teste foram armazenadas para posterior análise.

\section{Caracterização do biodiesel}

As amostras do biodiesel sintetizado, bruto e lavado, foram analisadas em conformidade com o Regulamento Técnico ANP n 3/2014. As características analisadas neste trabalho foram índice de acidez, índice de refração, densidade a $20^{\circ} \mathrm{C}$, viscosidade cinemática a 40 ${ }^{\circ} \mathrm{C}$, teor de água, estabilidade oxidativa a $110^{\circ} \mathrm{C}$ e glicerina livre.

\section{Índice de acidez}

A conservação do biodiesel é indicada pelo índice de acidez (Ia), que é definida como a massa de hidróxido de potássio $(\mathrm{KOH})$ necessária para neutralizar os ácidos livres de um grama da amostra. Quando o índice apresenta altos valores, relaciona-se diretamente com os processos de hidrólise e de oxidação. ${ }^{27,28} \mathrm{O}$ método consiste em analisar uma quantidade conhecida de biodiesel com uma mistura de etanol e éter etílico, seguido de titulação do ácido graxo livre com solução etanólica de $\mathrm{KOH}$. 
Em um Erlenmeyer de $125 \mathrm{~mL}$, foram colocados $2 \mathrm{~g}$ da amostra do biodiesel. Em seguida, foram adicionados $25 \mathrm{~mL}$ da solução neutra de éter etílico mais etanol na proporção, em volume de 2:1 respectivamente. Adicionaram-se à solução três gotas de fenolftaleína $1 \%$, que foi titulada com solução $\mathrm{KOH} 0,1 \mathrm{~mol} \mathrm{~L}^{-1}$ até a predominância de uma coloração rósea. $\mathrm{O}$ índice de acidez é determinado a partir da equação 1 .

$$
I_{a}=\frac{V \times N \times f \times 56,11}{P}
$$

em que: $I_{a}=$ índice de acidez ( $\mathrm{mg}$ de $\left.\mathrm{KOH} / \mathrm{g}\right) ; V=$ volume em $\mathrm{mL}$ de KOH gasto na titulação; $N=$ normalidade da solução de $\mathrm{KOH}$; $f=$ fator de correção da solução $\mathrm{KOH} ; P=$ massa em gramas da amostra.

As normas EN 14214, ASTM D6751 e o Regulamento Técnico n ${ }^{\circ}$ 3/2014 da ANP estabelecem limites máximos de acidez de 0,5 mg de $\mathrm{KOH} / \mathrm{g}$. 6,10,29,30

\section{Índice de refração}

O índice de refração (IR) é característico para cada tipo de óleo, pelos valores estabelecidos em certos limites. Está relacionado com o grau de saturação das ligações, mas é afetado por outros fatores, tais como: teor de ácidos graxos livres, oxidação, peróxidos e outros componentes. $^{12}$

Ajustou-se previamente o refratômetro de Abbé com água destilada (IR $20^{\circ} \mathrm{C}=1,333$ ) como referência. Colocaram-se duas gotas de amostra entre os prismas, focalizando para leitura. A leitura foi feita diretamente à temperatura do ambiente. Os prismas foram rigorosamente lavados com acetona e, posteriormente, secos com papel absorvente. O cálculo para a conversão do IR, em função da diferença das temperaturas, foi realizado por interpolação, como recomenda Moretto. ${ }^{31}$

\section{Densidade a $20^{\circ} \mathrm{C}$}

A densidade foi determinada em um picnômetro de $25 \mathrm{~mL} \mathrm{em}$ um banho termostatizado a $20{ }^{\circ} \mathrm{C}$.

Primeiramente, pesou-se o picnômetro vazio e seco. Para transportar o picnômetro, utilizou-se um pedaço de papel-toalha para evitar o contato direto com as mãos. Na sequência, o picnômetro foi completado com água destilada. Tampou-se o picnômetro, de forma que o excesso de água escorresse pelo capilar. Tomou-se o cuidado de não deixar ocorrer a formação de bolhas de ar no interior do picnômetro. Aguardaram-se 15 minutos para que o equilíbrio térmico fosse atingido.

Pesou-se o picnômetro com água. O procedimento de pesagem foi repetido por mais duas vezes. A diferença entre essa massa e a massa do picnômetro vazio permitiu determinar a massa de água contida no picnômetro e, por meio da densidade, determinou-se o volume do picnômetro.

Da mesma forma que se determinou a massa da água destilada, a massa do biodiesel também foi determinada.

A norma europeia estabelece valores de densidade entre 860 a $900 \mathrm{~kg} \mathrm{~m}^{-3}$. A Resolução ${ }^{\circ} 45 / 2014$ da $\mathrm{ANP}^{6}$ fixa uma faixa de valores entre 850 a $900 \mathrm{~kg} \mathrm{~m}^{-3}$. Na resolução brasileira, fica estabelecido ainda que o biodiesel produzido tenha um prazo máximo de um mês, a contar da data de certificação, para ser comercializado. Depois desse prazo, deve ser realizada uma nova análise da densidade a $20{ }^{\circ} \mathrm{C}$; existindo diferença inferior a $3 \mathrm{~kg} \mathrm{~m}^{-3}$, em relação ao valor do certificado, deverão ser novamente analisados o teor de água, o índice de acidez e a estabilidade oxidativa a $110^{\circ} \mathrm{C}$. Se a diferença for superior a $3 \mathrm{~kg} \mathrm{~m}^{-3}$, deverão ser reavaliados todos os parâmetros da resolução.

\section{Viscosidade cinemática a $40{ }^{\circ} \mathrm{C}$}

A viscosidade cinemática é a medida da resistência ao escoamento sob ação da gravidade de certa massa de fluido em relação ao seu volume, ou seja, é a razão entre a viscosidade dinâmica e a massa específica do fluido.

Foi medido o tempo de escoamento do biodiesel por meio de um viscosímetro capilar, e o produto entre a medida de tempo de fluxo e a constante de calibração do tubo viscosímetro é o valor referente à viscosidade cinemática (ASTM D445). ${ }^{32}$

O limite aceito para a viscosidade cinemática a $40{ }^{\circ} \mathrm{C}$, segundo as normas europeia, americana e brasileira, está entre 3 e $6 \mathrm{~mm}^{2} \mathrm{~s}^{-1}$.

\section{Teor de água}

A determinação do teor de água para o biodiesel está de acordo com o método da ASTM D6304. ${ }^{6}$ As variações no teor de água das alíquotas foram analisadas em um equipamento Karl Fischer.

O valor máximo permitido no teor de água é de $200 \mathrm{mg} \mathrm{kg}^{-1}$ e, para efeito de fiscalização no Brasil, nas autuações por não conformidade, será admitida variação de $+50 \mathrm{mg} \mathrm{kg}^{-1}$ no limite do teor de água no biodiesel para o produtor e de $+150 \mathrm{mg} \mathrm{kg}^{-1}$ para o distribuidor. ${ }^{33}$

\section{Estabilidade oxidativa a $110^{\circ} \mathrm{C}$}

Os ensaios de estabilidade oxidativa foram realizados em quatro repetições, utilizando equipamento Rancimat (873), marca Metrohm com base na norma EN 14112, EN 15751. No método, três gramas da amostra são envelhecidos a $110^{\circ} \mathrm{C}$, sob fluxo constante de ar $\left(10 \mathrm{~L} \mathrm{~h}^{-1}\right)$. $\mathrm{O}$ rápido aumento da taxa de oxidação é expresso pelo aumento de condutividade na água deionizada, cujos voláteis são captados, sendo ocasionado pela formação de peróxido e de voláteis. Como resultado esperado, determina-se o período de indução ou ponto de inflexão (PI), que, segundo a Resolução no 45/2014, ${ }^{6}$ deve ser superior a 8 horas. Os cálculos dos períodos de indução foram realizados com o auxílio do programa que acompanha o equipamento (Software 873 - Rancimat).

\section{Glicerina livre}

A determinação da glicerina ${ }^{34,35}$ livre foi realizada por método iodométrico, com ácido periódico, em que $3 \mathrm{~g}$ da amostra de biodiesel foram colocados em um funil de separação de $250 \mathrm{~mL}$. Adicionaram-se $20 \mathrm{~mL}$ de água destilada e $0,5 \mathrm{~mL}$ de ácido sulfúrico (1:4 v:v), agitando-se para homogeneizar a solução. A solução permaneceu em repouso, até a separação das duas fases. A fase mais densa (mais clara) foi retirada e colocada em um Erlenmeyer de $250 \mathrm{~mL}$.

A glicerina livre foi determinada com a solução retirada do funil de separação. Foram adicionados $50 \mathrm{~mL}$ de solução de periodato de sódio $5,5 \mathrm{~g} \mathrm{~L}^{-1}$ deixando em repouso por 10 minutos. Em seguida, adicionaram-se $4 \mathrm{~g}$ de bicarbonato de sódio e $2 \mathrm{~g}$ de iodeto de potássio, agitando para homogeneizar. Essa solução foi titulada com arsenito de sódio $0,1 \mathrm{~mol} \mathrm{~L}^{-1}$ até a coloração ficar um pouco mais clara; em seguida, adicionaram-se 3 gotas de solução de amido $(1 \%, \mathrm{~m} / \mathrm{v})$, continuando a titulação até a viragem, ou seja, quando a solução apresentava-se incolor.

O cálculo foi baseado na equação 2 abaixo:

$$
\text { Glicerina livre } / \%=\frac{\left(V_{b}-V_{s}\right) \times T \times 0,1}{m}
$$

em que: $\mathrm{V}_{\mathbf{b}}=$ volume $(\mathrm{mL})$ da solução de arsenito consumido na titulação do branco; $V_{s}=$ volume $(\mathrm{mL})$ da solução de arsenito consumido na titulação da amostra; $T$ = título da solução de arsenito de sódio; $m$ = massa $(\mathrm{g})$ da amostra do biodiesel. 
A Resolução ANP n ${ }^{\circ} 45$, de 25 de agosto de 2014, em seu anexo, estabelece que a quantidade máxima de glicerina livre no biodiesel B100 é de $0,02 \%$ em massa. ${ }^{36}$

\section{Caracterização das fibras de bagaço}

\section{Quantificação de grupos carboxilatos em BCAC}

A quantificação foi feita determinando pela diferença entre a percentagem de $\mathrm{Na}$ presente na fibra quimicamente modificada (BCAC) e a fibra não modificada (BCAP). A percentagem de grupos carboxilatos de sódio presente nas fibras BCAC foi de $6,4 \%$ em massa. Isso mostra que, mesmo sendo uma modificação superficial, quase $10 \%$ das fibras foram modificadas.

\section{Difração de raios $X(D R-X)$}

$\mathrm{O}$ equipamento utilizado para a realização das análises de difração de raios X foi da marca Shimadzu, modelo Labx XRD6000 , operando na tensão de $40 \mathrm{kV}$, corrente de $30 \mathrm{~mA}$ e radiação $\mathrm{Cu} \mathrm{K \alpha}$. Os difratogramas de raios $\mathrm{X}$ das fibras de bagaço de cana-de-açúcar (bruto, purificado e carboximetilado) foram obtidos à temperatura ambiente com intervalo de 5 a $40^{\circ} 2 \theta$ e uma velocidade de varredura de $2^{\circ} 2 \theta \mathrm{min}^{-1}$. A determinação do índice de cristalinidade (CrI) por difração de raios $\mathrm{X}$ foi calculada pela Equação (3) baseada no método de Segal, método desenvolvido para estimar o grau de cristalinidade de celulose nativa, em relação à reflexão em $2 \theta=18^{\circ}{ }^{36}$

$$
C r I=\frac{I_{002}-I_{a m}}{I_{002}} \times 100
$$

em que $\mathrm{I}_{002}$ representa a intensidade máxima em $2 \theta=23^{\circ}$ e $\mathrm{I}_{\mathrm{am}} \mathrm{em}$ $2 \theta=18^{\circ}$.

\section{Microscopia eletrônica de varredura (MEV)}

Os três tipos de bagaço (puro, purificado e carboximetilado) foram analisados em um microscópio eletrônico de varredura da marca TESCAN e modelo VEGA 3, operando na faixa de tensão de $5 \mathrm{kV}$. As amostras foram colocadas em um suporte metálico (estágio) e previamente recobertas com uma fina camada de ouro. Em seguida, as imagens foram obtidas em diferentes pontos das amostras e em magnificações na ordem de 30, 10, 5 e 1 kx. A partir da análise das imagens, foi possível observar as modificações morfológicas superficiais nas diferentes fibras.

\section{Diâmetro dos poros/tamanho das partículas}

O equipamento ASAP 2020 da micrometrics foi utilizado na adsorção física de nitrogênio a $-196{ }^{\circ} \mathrm{C}$ para se determinar a área superficial da fibra carboximetilada (BCAC).

\section{Calorimetria exploratória diferencial (DSC)}

As curvas por calorimetria exploratória diferencial (DSC) foram obtidas em um calorímetro da marca TA Instruments, modelo 2910 , com um aquecimento de $25-550{ }^{\circ} \mathrm{C}$, uma taxa de $10{ }^{\circ} \mathrm{C} \mathrm{min}-1$ e fluxo de $50 \mathrm{ml} \mathrm{min}^{-1}$ de $\mathrm{N}_{2}$

\section{Infravermelho com transformada de Fourier (FTIR)}

As análises por espectroscopia na região do infravermelho foram realizadas para duas amostras, BCAP e BCAC, em um espectrofotômetro de Infravermelho por Transformada de Fourier (modelo IR PRESTIGE-21, marca Shimadzu), em pastilhas de $\mathrm{KBr}$ na proporção mássica de 1:100, com 32 varreduras, com resolução de $4 \mathrm{~cm}^{-1}$.

\section{RESULTADOS E DISCUSSÃO}

\section{Caracterização do biodiesel}

Tabela 1. Valores obtidos da análise físico-química dos parâmetros analisados

\begin{tabular}{|c|c|c|c|}
\hline Parâmetros & $\begin{array}{l}\text { Biodiesel de } \\
\text { óleo de soja } \\
\text { bruto }\end{array}$ & $\begin{array}{l}\text { Biodiesel de } \\
\text { óleo de soja } \\
\text { lavado }\end{array}$ & Limite ANP \\
\hline $\begin{array}{l}\text { Índice de acidez, máx. } \\
\left(\mathrm{mg} \mathrm{KOH} \mathrm{g}^{-1}\right)\end{array}$ & 0,23 & 0,25 & 0,5 \\
\hline Índice de refração & 1,4530 & 1,4545 & - \\
\hline Densidade a $20^{\circ} \mathrm{C}\left(\mathrm{kg} \mathrm{m}^{-3}\right)$ & 872,0 & 883,0 & $850,0-900,0$ \\
\hline $\begin{array}{l}\text { Viscosidade cinemática a } \\
40{ }^{\circ} \mathrm{C}\left(\mathrm{mm}^{2} \mathrm{~s}^{-1}\right)\end{array}$ & 7,0 & 6,0 & $3,0-6,0$ \\
\hline Teor de água, máx. $\left(\mathrm{mg} \mathrm{kg}^{-1}\right)$ & 1355,5 & 4119,7 & 200 \\
\hline $\begin{array}{l}\text { Estabilidade oxidativa a } \\
110^{\circ} \mathrm{C} \text { (horas) }\end{array}$ & 8,1 & 3,2 & 8,0 \\
\hline $\begin{array}{l}\text { Glicerina livre, máx. } \\
\text { (\% massa) }\end{array}$ & 0,11 & 0,013 & 0,02 \\
\hline
\end{tabular}

\section{Caracterização das fibras}

Análise térmica - DSC

O gráfico da Figura 1 apresenta os resultados de DSC para as três fibras: bruta - BCA, purificada - BCAP e purificada e carboximetilada em sua superfície - BCAC, comparado com 100 gramas da fibra BCAC, após adsorção dos contaminantes do biodiesel bruto por 24 horas.

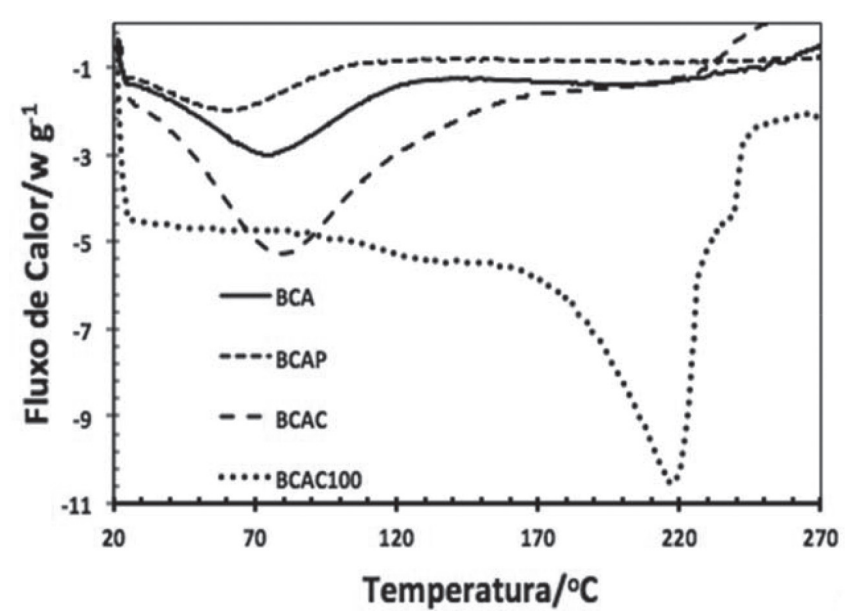

Figura 1. DSC das três fibras de bagaço e uma de bagaço após adsorver glicerol e água do biodiesel bruto por 24 horas

Nota-se da Figura 1 uma maior quantidade de água adsorvida na fibra modificada BCAC, pela sua característica mais hidrofílica, do que as outras duas fibras. A saída de água das fibras pode ser notada por volta de $80{ }^{\circ} \mathrm{C}$. Por outro lado, quando glicerol e água estão presentes, a banda de saída de água da fibra não apresenta um pico característico, devido, provavelmente, à presença dos outros contaminantes, como os íons e o metanol da mistura reacional do processo de transesterificação. No caso do glicerol, a dessorção da fibra dá-se por volta de $220^{\circ} \mathrm{C}$, como pode ser visto na Figura 1 , que é comprovado pelos resultados de DSC, do glicerol puro e de duas fibras adsorvidas, com diferentes quantidades de glicerol (Figura 2). 


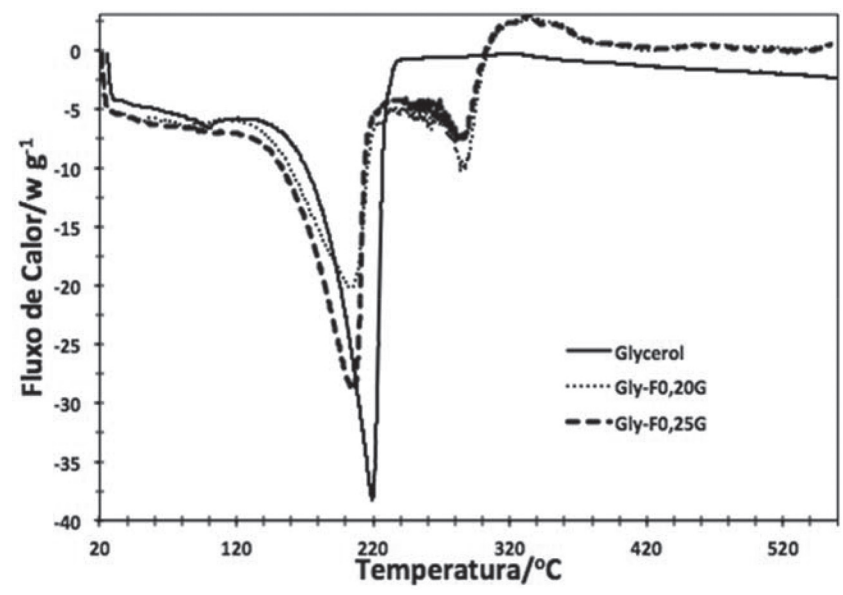

Figura 2. DSC do glicerol puro e adsorvido em duas fibras usadas neste experimento ( $B C A C 0,20 \mathrm{~g}$ e BCAC 0,25 g), partindo de uma solução aquosa de glicerol

\section{Difração de raios $X$}

Na Tabela 2, têm-se os resultados de difração de raios X para as três fibras. A fibra bruta (BCA) e a fibra modificada superficialmente (BCAC) apresentam uma cristalinidade muito próxima, ao passo que a fibra purificada (BCAP) apresenta uma cristalinidade diferente. Pelo fato de as fibras serem compostas de dois constituintes principais, a celulose ( 40 a $60 \%)$ e a lignina ( 20 a 40\%), a carboximetilação deve ocorrer nas duas estruturas, formando a carboximetilcelulose de sódio e a carboximetillignina de sódio. $\mathrm{O}$ aumento da cristalinidade da fibra purificada deve-se ao processo de purificação, que elimina principalmente graxas e ceras presentes no bagaço. A modificação química das fibras é evidente quando se observa, dos dados da Tabela 2, a grande queda dos valores de CrI para a fibra modificada quimicamente (BCAC) em relação à fibra purificada (BCAP). Estes resultados são uma confirmação da modificação química da superfície das fibras.

Tabela 2. Valores dos índices de cristalinidade (CrI) das fibras baseado no método de Segal ${ }^{37}$

\begin{tabular}{cccc}
\hline Fibras & BCA & BCP & BCAC \\
\hline CrI/\% & 15,8 & 26,4 & 16,3 \\
$\mathrm{I}_{002}$ & 786 & 860 & 540 \\
$\mathrm{I}_{\mathrm{am}}$ & 662 & 634 & 452 \\
\hline
\end{tabular}

Outra confirmação da modificação química nas fibras é o resultado da análise por espectroscopia no infravermelho-FTIR. A carboximetilação das fibras, pelo processo utilizado, provoca uma deslignificação, devido, principalmente, à alta concentração de base no meio, mas também devido à reação química de carboximetilação da celulose, que provoca a abertura das fibras e liberação da lignina mais lábil. Bandas atribuídas à lignina e às hemiceluloses desaparecem no espectro após a modificação. Dentre elas, destacam-se os sinais em $1.240 \mathrm{~cm}^{-1}, 1.370 \mathrm{~cm}^{-1}, 1.470 \mathrm{~cm}^{-1} \mathrm{e} 1.692 \mathrm{~cm}^{-1}$. Esses sinais podem ser atribuídos: $\left(1.240 \mathrm{~cm}^{-1}\right)$ - à vibração do anel aromático ou estiramento das ligações $\mathrm{C}-\mathrm{C}$ e $\mathrm{C}-\mathrm{O}$ ambos na lignina; (1.370 $\mathrm{cm}^{-1}$ ) - à torção da ligação $\mathrm{C}-\mathrm{H}$ na celulose, nas hemiceluloses e na lignina; $\left(1.470 \mathrm{~cm}^{-1}\right)$ - à deformação da ligação C-H na lignina; (1.692 $\mathrm{cm}^{-1}$ ) - ao estiramento da ligação $\mathrm{C}=\mathrm{O}$ na lignina ${ }^{38,17}$ Por outro lado, dois sinais importantes crescem em $1.600 \mathrm{~cm}^{-1} \mathrm{e}$ em $1.420 \mathrm{~cm}^{-1}$ após a modificação. São sinais atribuídos à carbonila, resultante da carboximetilação da celulose e da lignina. O primeiro é um sinal forte atribuído ao estiramento assimétrico do íon carboxilato e o segundo é um sinal fraco atribuído ao estiramento simétrico do mesmo íon. ${ }^{39}$

\section{Microscopia eletrônica de varredura (MEV)}

As imagens obtidas por MEV estão apresentadas na Figura 3 para as diferentes fibras de bagaço de cana-de-açúcar (bruto, purificado e carboximetilado). Da análise das imagens, é possível observar que os materiais têm formatos, tamanhos e texturas diferentes, o que implica tamanhos de áreas superficiais das partículas também diferentes. Tais mudanças exercem papéis diferentes na adsorção dos contaminantes do biodiesel.
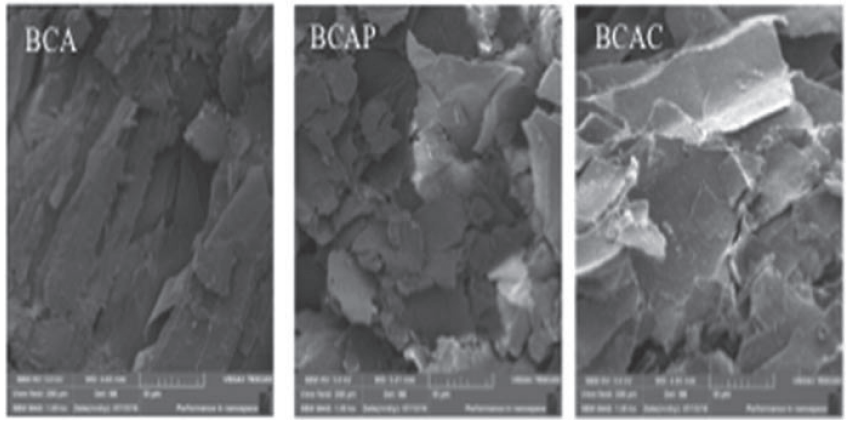

Figura 3. Imagens de MEV das fibras de bagaço antes da purificação (BCA), após purificação (BCAP) e carboximetilada superficialmente (BCAC)

As fibras de bagaço são materiais lignocelulósicos, nos quais a celulose é envolvida em uma matriz amorfa de polioses e lignina. A matriz amorfa age como uma barreira natural ao ataque de micro-organismos e/ou enzimas e torna esses materiais estruturalmente rígidos e pouco reativos. ${ }^{40} \mathrm{~A}$ biomassa lignocelulósica, geralmente, contém $32-48 \%$ em massa de celulose, $19-24 \%$ de hemicelulose, $23-32 \%$ de lignina e uma pequena quantidade de cinzas e extrativos. As modificações nas fibras ocasionadas pelo processo de carboximetilação ocorrem preferencialmente na estrutura da celulose (celobiose) e da lignina (grupo fenil propano- $\mathrm{C}_{9}$ ), que as tornam hidrofílicas. Como as modificações só ocorrem na superfície, as fibras não se solubilizam completamente.

\section{Diâmetro médio dos poros/tamanho médio das partículas}

A área superficial determinada por fisissorção (ASAP) para a fibra carboximetilada (BCAC) apresentou os seguintes resultados: 2,0589 $\pm 0,2511 \mathrm{~m}^{2} \mathrm{~g}^{-1}$ e diâmetro de poro de $9,8132 \mathrm{~mm}$. As isotermas de adsorção e dessorção mostram uma histerese de adsorção para esse material que envolve a adsorção do $\mathrm{N}_{2}$ em diferentes pressões aplicadas. Apesar de ser uma área reduzida, quando comparada com a área do carvão ativado, que tem $3.000 \mathrm{~m}^{2} \mathrm{~g}^{-1}$, pelo mesmo método de determinação, a adsorção deve-se dar mais pela interação hidrofílica das partículas do adsorvente com os contaminantes.

\section{Adsorção no biodiesel bruto}

A Figura 4 mostra o resultado dos cálculos da área do sinal de DSC para o adsorvente (fibras) e DTA para o biodiesel, na região de saída dos contaminantes (entre $20^{\circ} \mathrm{C}$ e $300^{\circ} \mathrm{C}$ ), em função da massa das fibras adicionadas ao biodiesel bruto.

Estes resultados de DSC e DTA mostram que o biodiesel tem uma significativa redução dos contaminantes (glicerol e água), quando tratado por 24 horas com diferentes quantidades de fibras modificadas (BCAC). Pode-se observar também que há saturação das fibras (resultando em um mínimo de contaminantes do biodiesel e máximo das fibras) quando a quantidade de fibras adsorventes se aproximam de $1 \mathrm{~g}$. Verifica-se também que a saturação dá-se para valores muito próximos daqueles do biodiesel totalmente seco (Regulamento Técnico $\left.n^{\circ} 3 / 2014\right){ }^{6}$ Estes resultados foram quantificados, a partir dos dados das bandas na região entre $50{ }^{\circ} \mathrm{C}$ e $250{ }^{\circ} \mathrm{C}$, das medidas de DTA. 


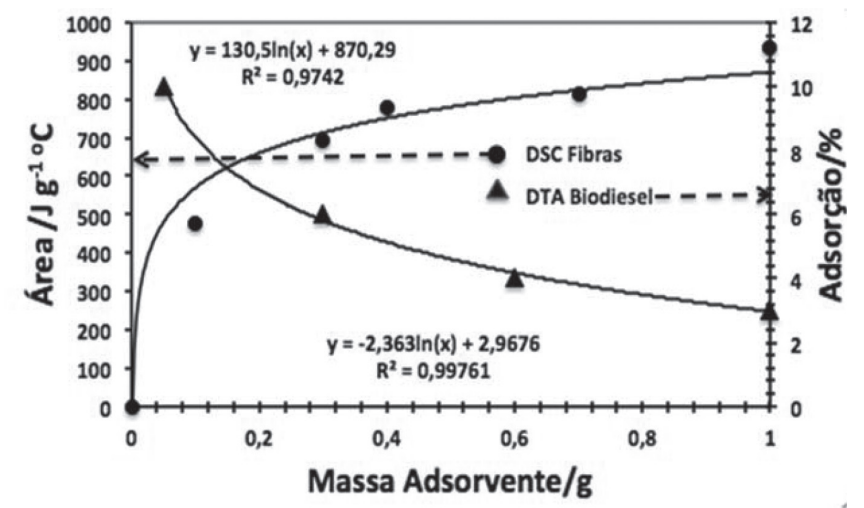

Figura 4. Área do sinal de DSC determinado para as fibras e DTA do biodiesel para contaminantes no biodiesel bruto em função da massa adicionada

\section{Adsorção com o biodiesel lavado}

A Figura 5 mostra a análise de DSC para o biodiesel após sua lavagem com água.

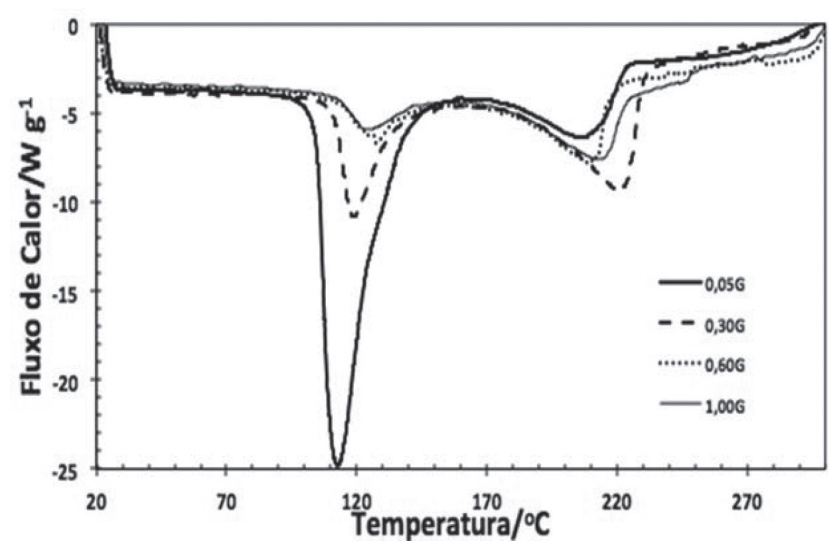

Figura 5. DSC do biodiesel lavado após adsorção de diferentes massas de fibras de bagaço (BCAC)

Nota-se, da Figura 5, a remoção dos contaminantes do biodiesel após as lavagens com água destilada. A lavagem com água é feita para retirada de contaminantes presentes em biodiesel produzidos por reação de transesterificação. Tais contaminantes (que estão presentes em maior proporção no biodiesel bruto) são, além da água e do glicerol, os íons do catalisador $\left(\mathrm{K}^{+}\right.$e $\left.\mathrm{OH}^{-}\right)$e os álcoois de cadeia curta (metanol).

Da figura, pode-se observar que a adsorção de água nas fibras (quantificada pela sua saída com a temperatura), em torno de $100{ }^{\circ} \mathrm{C}$, é mais evidente do que nas fibras que adsorveram os contaminantes no biodiesel bruto. Do biodiesel, grande parte dos contaminantes presentes foi retirada pela lavagem. A lavagem faz com que a quantidade de glicerol diminua significativamente, como é esperado, e aumente a quantidade de água, e como pode ser visto na endoterma do glicerol por volta de $220^{\circ} \mathrm{C}$, bem menos intensa do que no biodiesel bruto. A lavagem do biodiesel não é um bom método de purificar o biodiesel, devido a seu caráter hidrofílico, necessitando de retirada posterior da água e sua manutenção seco.

É possível quantificar o que se observa na Figura 5, medindo-se as áreas dos picos da saída de água em torno de $100{ }^{\circ} \mathrm{C}$ e a soma destes valores com as áreas da saída do glicerol em torno de $220^{\circ} \mathrm{C}$. Todos esses contaminantes promovem a deterioração dos motores dos veículos após a queima do combustível (Regulamento Técnico $\left.n^{\circ} 3 / 2014\right) .{ }^{6}$ Como pode-se depreender dos resultados de DSC, resta alguma água e glicerol recalcitrantes no biodiesel. O biodiesel é bastante hidrofílico e a eliminação da água constitui-se em uma

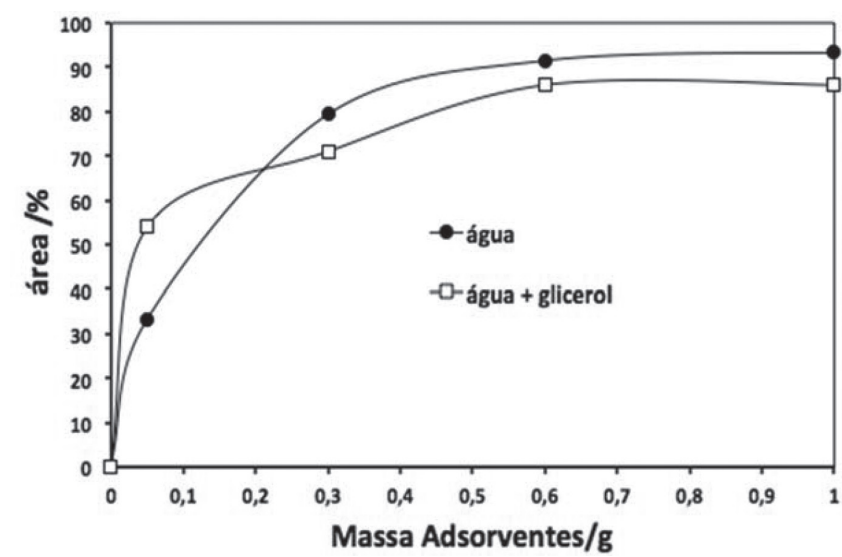

Figura 6. Áreas dos picos referentes à água em torno de $110^{\circ} \mathrm{C}$ e água mais o glicerol em torno de $220^{\circ} \mathrm{C}$

das grandes dificuldades à preparação do biodiesel em padrão de qualidade adequado. O glicerol, por ser um tri-álcool de cadeia curta, é muito solúvel em água. Dessa forma, os dois componentes estão associados (assim como os outros contaminantes) e devem sair no processo de adsorção nas fibras, como se depreende das Figuras 5 e 6.

À medida que a massa de adsorvente cresce em contato com o biodiesel por 24 horas, a quantidade de contaminantes presente no biodiesel decresce. Pode-se também inferir que ocorre uma saturação da adsorção, quando a massa de adsorvente chega próximo de $0,7 \mathrm{~g}$.

A Figura 7 mostra o resultado de análise da quantidade de glicerol livre, obtido por titulação por método da literatura, nos dois biodieseis, bruto e lavado, comparando-se este último com os dados de área do sinal do glicerol da Figura 6. ${ }^{34,10}$

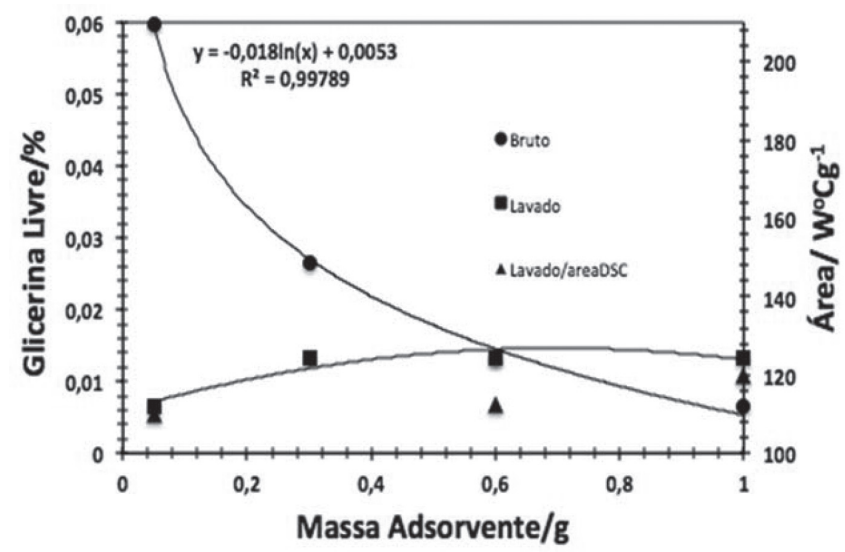

Figura 7. Percentagem de glicerina livre presente no biodiesel (Bruto e Lavado) determinado por titulação e pela área DSC em torno de $220^{\circ} \mathrm{C}$ da Figura 6

Nota-se a queda exponencial (com um coeficiente de correlação de $99,8 \%$ ) do conteúdo de glicerol no biodiesel bruto em função da massa de adsorvente adicionado. Uma estimativa para se determinar a massa necessária de fibras (BCAC) para remover a quantidade de glicerol no biodiesel pode ser feito baseado na equação do decaimento. Por esse método, a massa necessária seria de $1,34 \mathrm{~g}$ de fibra.

Para o biodiesel lavado, a quantidade de glicerol livre no biodiesel fica aproximadamente constante com a massa de adsorvente adicionado, determinado pelo mesmo método. O resultado é similar quando quantificado pela área do sinal de saída glicerol $\left(\sim 220{ }^{\circ} \mathrm{C}\right)$ observado pelos dados de DSC, determinados no biodiesel lavado verificado na Figura 6. 


\section{CONCLUSÃO}

As fibras de bagaço de cana-de-açúcar purificadas, e com as superfícies modificadas por carboximetilação, produziram resultados positivos na adsorção de contaminantes do biodiesel: água e glicerol, tanto no biodiesel bruto quanto no biodiesel lavado. A análise térmica permitiu quantificar a remoção da água e do glicerol em cerca de 98 massa\%. Os testes realizados com diferentes massas do material adsorvente mostraram que a saturação das fibras começa a ocorrer por volta de $0,7 \mathrm{~g}$ de fibras. A massa estimada para adsorver todo o glicerol livre no biodiesel bruto é de 1,34 g, ou cerca de $134 \mathrm{~g}$ para cada litro de biodiesel $(13,4 \%)$. O tempo escolhido para o contato entre o adsorvente e o adsorbato (fibras de bagaço e biodiesel de óleo de soja) foi de somente 24 horas; a otimização do tempo passa a ser um tema relevante a se considerar em pesquisas futuras. Nossos resultados mostram a possibilidade de se usar um método alternativo eficiente para se eliminar proporções importantes todos os contaminantes do biodiesel, evitando-se o uso de grandes volumes de água como é, hoje, convencionalmente adotado na produção industrial de biodiesel.

\section{REFERÊNCIAS}

1. http://horizontegeografico.com.br/exibirMateria/220, acessada em novembro de 2017.

2. http://www.ibge.gov.br/home/geociencias/cartografia/default_territ_area. shtm, acessada em novembro de 2017.

3. http://www.anp.gov.br/?id=470, acessada em novembro de 2017.

4. http://www.brasil.gov.br/infraestrutura/2011/12/pais-revoluciona-o-usoe-a-producao-de-biocombustivel, acessada em novembro de 2017.

5. http://www.planalto.gov.br/ccivil_03/_ato2015-2018/2016/lei/L13263. $\mathrm{htm}$, acessada em novembro de 2017.

6. http://nxt.anp.gov.br/NXT/gateway.dll/leg/resolucoes_anp/2014/agosto/ ranp\%2045\%20-\%202014.xml?f=templates $\$ \mathrm{fn}=$ document - frame. $\mathrm{htm} \$ 3.0 \$ \mathrm{q}=\$ \mathrm{x}=\$ \mathrm{nc}=906$, acessada em novembro de 2017.

7. http://biodiesel.org/what-is-biodiesel/biodiesel-fact-sheets, acessada em novembro de 2017.

8. http://www.anp.gov.br/wwwanp/images/publicacoes/boletinsanp/ Boletim_Mensal_do_Biodiesel/Boletim_Biodiesel_JANEIRO_2017. pdf, acessada em novembro de 2017.

9. http://www.agricultura.gov.br/vegetal/culturas/soja, acessada em novembro de 2017.

10. Lôbo, I. P.; Ferreira, S. L. C.; Cruz, R. S.; Quim. Nova 2009, 32, 1596.

11. Fontaras, G.; Kousoulidou, M; Karavalakis, G.; Tzamkiozis, T; Tzamkiozis, P.; Ntziachristos, L.; Ntziachristos. E.; Stournas, S.; Samaras, S.; Environ. Pollut. 2010, 158, 1451.

12. Borges, K. A.; Dissertação de mestrado, Universidade Federal de Uberlândia, Brasil, 2011.

13. Atadashi, I. M.; Aroua, M. K.; Aziz, A. A.; Sulaiman, N. M. N.; Appl. Energy 2011, 88, 4239.

14. Stojkovic, I. J.; Stamenkovic, O. S.; Povrenovic, D. S.; Veljkovic, V. B.; Renewable Sustainable Energy Rev. 2014 32, 1.

15. Savaliya, M. L.; Dorajiya, B. D.; Dholakiya, B. Z.; Sep. Purif. Rev. 2015, $44,28$.
16. Silva, L. G.; Tese de doutorado, Universidade Federal de Uberlândia, Brasil, 2014.

17. Carvalho, W. S. Martins, D. F.; Gomes, F. R.; Leite, I. R.; Silva, L. G.; Ruggiero, R.; Richter, E. M; Biomass Bioenergy 2011, 35, 3913.

18. Rico, J. A. P.; Sauer, I. L.; Renewable Sustainable Energy Rev. 2015, 45, 513.

19. Vaz Junior, S.; Embrapa Agroenergia 2011, 176.

20. Ragauskas, A. J. Beckham, G. T.; Biddy, M. J.; Chandra, R.; Chen, F.; Davis, M. F.; Davison, B. H.; Dixon, R. A.; Gilna, P.; Keller, M.; Langan, P.; Naskar, A. K.; Saddler, J. N.; Timothy, J.; Tuskan, T. G. A.; Wyman, C. E.; Science 2014, 344, 1246843.

21. h t t p ://www.con ab.gov.br/OlalaCMS/uploads/ arquivos/16_08_17_10_07_35_boletim_cana_portugues_-_2o_lev__16-17.pdf, acessada em novembro de 2017.

22. Césare, M. F. C.; Castillo, L.; Beteta, V. A.; Calle, J. L. M.; Léon, J. J. C.; Revista del la Sociedad Química del Perú 2010 76, 25.

23. Vasques, E. C.; Dissertação de mestrado, Universidade Federal do Paraná, Brasil, 2010.

24. Cavallari, P. I.; Trabalho de conclusão de curso, Universidade de São Paulo, Brasil, 2012.

25. http://aqa.org.ar/images/anales/pdf99/cd/Qca.\%20Industrial/71.pdf, acessada em novembro de 2017.

26. Silva, G. M.; Quadri, M. B.; Costa, A. E.; Dias, R.; Resumos do congresso brasileiro de engenharia química em iniciação científica, Uberlândia, Brasil, 2009.

27. Costa, A. E; Tese de doutorado, Universidade Federal de Santa Catarina, Brasil, 2010.

28. Lora, E. E. S.; Venturini, O. J.; Biocombustíveis, $1^{\text {a }}$ ed., Interciência: Rio de Janeiro, 2012.

29. Dantas, M. B.; Tese de doutorado, Universidade Federal da Paraíba, Brasil, 2010.

30. Serqueira, D. S.; Dissertação de Mestrado, Universidade Federal de Uberlândia, Brasil, 2014.

31. Moretto, E.; Tecnologia de óleos e gorduras vegetais na indústria de alimentos, $1^{\mathrm{a}}$ ed., Varela: São Paulo, 1998.

32. Silva, H. K. T. A.; Dissertação de Mestrado, Universidade Federal do Rio Grande do Norte, Brasil, 2011.

33. Atadashi, I. M.; Aroua, M. K.; Aziz, A. A.; Renewable Sustainable Energy Rev. 2010, 14, 1999.

34. Gonçalves Filho, L. C.; Micke, G. A.; J. Chromatogr. A 2007, 1154, 477.

35. Lôbo, I. P.; Ferreira, S. L. C.; Cruz, R. S.; Quim. Nova 2009, 32, 1596.

36. http://nxt.anp.gov.br/NXT/gateway.dll?f=templates\&fn=default. htm\&vid=anp:10.1048/enu, acessada em novembro de 2017.

37. Segal, L.; Creely, J. J.; Martin, A. E.; Conrad, C. M.; Text. Res. J. 1959, $29,786$.

38. Xu, F.; Yu,J.; Tesso,T.; Dowell, F; Wang, D.; Appl. Energy 2013, 104, 801.

39. Silverstein, R. M.; Webster, F. X.; Kiemle, D. J., Spectrometric identification of organic compounds, $7^{\text {th }}$ ed., John Willey \& Sons: Toronto, 2005.

40. Fengel, D.; Wegener, G. Wood Chemistry, Ultrastruture, Reactions, $1^{\text {st }}$ ed., Walter de Gruyter: Berlin, 1989. 